\title{
Syntactic Position and the Readings of 'Manner' Adverbs'
}

\author{
Benjamin Shaer \\ The British Institute in Paris, University of London \\ bshaer@ims.uni-stuttgart.de
}

\begin{abstract}
In this study, I investigate the positions and interpretations available to 'manner' adverbs in English. My central claim, contra Wyner $(1994,1998)$, is that an association does exist between 'manner' adverb positions and interpretations, which is best characterized in terms of Peterson's (1997) distinction between 'restrictive' and 'non-restrictive' modification. I also claim, however, that the association in question is not as general as commonly claimed; and, in particular, does not apply directly to 'manner' adverbs in 'fronted' and 'parenthetical' positions, which require special syntactic description.
\end{abstract}

\section{Introduction}

A good deal of linguistic research has been devoted to 'manner' adverbs in English - a class of adverbs that may be characterized informally as those that occur (at least) in sentence-final position without preceding pause, and in this position describe some manner in which the situation designated by the VP occurs or is performed. What has been of especial interest here is that adverbs in this class occur not only in the 'lower', VP-internal position just mentioned but also in a 'higher', VP-external position, and receive different readings in these respective positions. This observation, as offered in McConnell-Ginet (1982) and elsewhere, is illustrated in 1:

(1) a. Louisa departed rudely.

b. Louisa rudely departed.

(ibid., $160,(37 b, a))$

The adverb rudely in the 'lower' position, as in the (a) sentence, receives a reading whereby Louisa departed in a rude manner; whereas the adverb in the 'higher' position, as in the (b) sentence, receives a reading whereby her act of departing was itself rude. The basic claim from which these two kinds of interpretations follow is that "VP-internal adverbs "restrict" the range of events referred to, whereas VP-external adverbs take verbal reference for granted and say something about the event or situation (partially) designated by the VP' (ibid., 159).

What makes this claim intriguing is that it is far-ranging but, in many cases, difficult to assess. Widely accepted in the literature and extended in various directions, it has given rise to what Wyner (1999) has called the 'association theory', according to which 'distinct semantic and/or syntactic properties are associated with distinct positions in the sentences', and 'adverbs are sensitive to and dependent on the properties of the positions.' Because there are many conspicuous gaps in the 'association' pattern, however, it remains unclear whether we have a truly general 'interface' pattern on our hands, or something more lexically driven. Wyner's own response to the 'association' claim is to reject it, arguing instead that the source

\footnotetext{
* I wish to thank Dennis Davy, Graham Katz, and Adrian Kempton, for helpful discussion of the themes treated here; Ruth Kempson, for graciously providing me with a copy of Kempson \& Meyer-Viol (1998); and Brendan Gillon, for drawing my attention to Peterson (1997).
} 
of the two readings just sketched is the properties of particular adverbs themselves rather than particular adverb positions, a given reading being preserved for a given adverb across different positions (see e.g. Wyner 1994: 197-98).

Wyner's claim is worth investigating not least because of its 'devil's advocate' response to the 'syntactization' of adverb meaning advanced in much recent research, which reached a kind of apogee with Cinque's (1996) ${ }^{1}$ claim for a universal hierarchy of adverb positions, each specific to a particular class of adverbs (see e.g. Ernst 1998, Shaer 1998 for a critique). But it is also worth investigating because it calls attention to the fact that an adverb's syntactic position is often not the well-charted map to its interpretation that most 'association' accounts suggest that it is. This is brought home by two adverb positions that Wyner draws attention to: 'fronted' and 'parenthetical' positions. As I shall be suggesting, the interpretation of adverbs in these positions casts doubt on rigid 'association' accounts like those of Cinque and others, according to which each semantic class of adverbs can be distinguished from each other class solely by its position in a syntactic tree.

While granting Wyner's insights, I shall nevertheless be showing that robust evidence does exist for the claim that the positions of 'manner' adverbs guide the kinds of readings that they receive. The key to reconciling Wyner's observations with the 'association' claim will be to rethink the nature of the contribution that 'higher' and 'lower' adverbs make to the interpretation of VPs and sentences; and to recognize how certain lexical properties of adverbs and certain adverb positions 'distort' this general association in predictable ways. Such considerations will permit an 'association' analysis that is far more sensitive to the adverb data and to the concerns that Wyner has raised.

The basic ingredients of this analysis consist in one main and three ancillary claims. My main claim is that an association does indeed exist between the positions and readings of 'manner' adverbs, and that contrasts in the readings of 'higher' and 'lower' adverbs are best captured in terms of a distinction between 'restrictive' and 'non-restrictive' modification, as proposed by Peterson (1997). My three ancillary claims follow from an examination of data that appear to be problematic for my main claim, which are related to (i) 'fronted' and 'parenthetical' occurrences of 'manner' adverbs, for which differences in position do not correlate directly with differences in interpretation; (ii) adverb positions in the auxiliary verb projections, for which differences in position likewise do not correlate directly with differences in interpretation; and (iii) particular adverbs that evince no contrast between 'higher' and 'lower' readings even in the 'higher' and 'lower' positions just described. These claims are as follows. First, 'fronted' and 'parenthetical' adverbs do not display the expected pattern because they do not have a fully determined syntactic (or, therefore, semantic) relation to the sentences to which they are attached. Next, the readings of 'manner' adverbs in different auxiliary positions appear to be synonymous because of the minor rôle that auxiliary verbs play compared to the main verb in designating a situation. However, as many studies have argued, they do play a key rôle in the creation of various 'derived' situations from 'basic' ones; and very subtle aspectual contrasts do emerge from the differential placement of 'manner' adverbs in otherwise synonymous sentences. Finally, and in a related vein, the synonymy claimed of 'higher' and 'lower' occurrences of various 'manner' adverbs is only apparent, two readings being more readily distinguishable on the basis of the 'Petersonian' distinction described above and in the context of VPs that make one or the other reading more salient.

The rest of this paper will be organized as follows. In section 2, I shall lay out the basic pattern of 'manner' adverbs in 'higher' and 'lower' positions as described by McConnell-

1 Eventually published as Cinque (1999). 
Ginet (1982), and offer additional data to support her generalization. In section 3, I shall address the three complications to the 'association' claim just described: (i) 'fronted' and 'parenthetical' adverb data; (ii) adverb positions in auxiliary verb projections; and (iii) particular adverbs in 'higher' and 'lower' positions that do not support a distinction between 'higher' and 'lower' readings. In section 4, I shall show that the very subtle contrasts that do emerge in this last class of adverbs have a natural characterization in terms of Peterson's (1997) distinction between 'restrictive' and 'non-restrictive' modification. Finally, in section 5 , I shall offer some concluding remarks.

\section{2. 'Higher' and 'Lower' Adverb Positions}

As noted abovc, a good deal of discussion has been devoted in the adverb literature to two basic positions: (i) one that is external to the main VP and appears between the main verb and the subject; and (ii) one that is internal to the main VP and appears sentence-finally. Although matters become somewhat more complicated once we consider a broader range of adverb positions, the patterns related to these two positions, which are the heart of the 'association' claim, are both robust and puzzling enough to warrant serious attention.

\subsection{McConnell-Ginet's (1982) Observations}

If we examine the interpretative contrasts between 'higher' and 'lower' positions that motivated McConnell-Ginet's (1982) 'association' claim, we find that the contrasts adduced by her, which include those in the following pairs of sentences, are indeed striking:

(2) a. Louisa rudely answered Patricia.

b. Louisa answered Patricia rudely.

(ibid., 159, (35))

(3) a. Minnie carelessly forgot her mother's birthday.

b. \#Minnie forgot her mother's birthday carelessly.

(ibid., 159, (32))

(4) a. Josie has furnished the house lavishly.

b. \#Josie lavishly has furnished the house.

c. Josie lavishly has installed $14 \mathrm{~K}$ gold faucets.

(ibid., 159, (33), (34))

Each of these pairs clearly illustrates the generalization given above that 'lower' adverbs "restrict" the range of events referred to', while 'higher' ones 'take verbal reference for granted and say something about the event or situation (partically) designated by the VP' (ibid., 159). Accordingly, (2a) 'can be construed as saying that Louisa's rudeness consisted in her having answered Patricia' at all, whereas [2b] locates the flaw in the manner of answering.' The sentences in (3) and (4) illustrate another possible consequence of adverb placement: namely, infelicity for a sentence when a 'lower' or a 'higher' adverb cannot be construed as respectively indicating a manner of acting or a comment on the situation being described. Thus, (3a), with a 'higher' adverb, asserts felicitously that Minnie was careless in having forgotten her mother's birthday; whereas ( $3 \mathrm{~b}$ ), with a 'lower' adverb, 'implicates that there is a special kind of forgetting which is careless', and is thus very odd. Contrariwise, (4a), with a 'lower' adverb, asserts felicitously that Josie has furnished her house in a lavish manner; whereas (4b), with a 'higher' adverb, asserts infelicitously 'that furnishing the house consti- 
What we find is a significant divergence from the pattern that we observed with VPs. This involves the loss of a correlation between 'higher' and 'lower' positions and readings, even though the single modifier in the AdjP and NP structures is structurally either higher or lower than the head that it modifies, and thus might be predicted to share the properties of its VP counterpart. Instead, the structurally 'high' adverb in (16a) receives a reading that is the counterpart of the 'lower' adverb in (6b); and the structurally 'low' adjective in (17a) receives both 'higher' and 'lower' readings. The availability of one or the other reading cannot be structurally conditioned, since there is no structural distinction here that could underwrite such a condition; and is presumably detemined by context. In other words, the readings available to the adverbs and adjectives in these examples indicate that the modifier positions in AdjP and NP structures reflect a collapsing of the two positions available in corresponding VP structures. As such, they provide indirect support for the existence of a structural distinction underlying 'higher' and 'lower' readings of 'manner' adverbs in the VP.

\section{Complications to the Higher/Lower Pattern}

In the preceding sections, we have seen compelling evidence for a tight relation between 'manner' adverb positions and interpretations - at least insofar as this applies to the two positions that we have been considering. Unfortunately, the clear picture that has emerged is obscured by the presence of various adverb data that are at odds with such a claim. Three sorts of data might be distinguished here: (i) those pertaining to 'fronted' and 'parenthetical' adverbs, whose positions in a syntactic tree are not related neatly to the readings that they receive; (ii) those pertaining to the various 'manner' adverb positions within auxiliary verb projections, which display no obvious interpretative contrasts amongst themselves; and finally, (iii) those pertaining to 'manner' adverbs that display no obvious interpretative contrasts even in the 'higher' and 'lower' positions described above. Let us consider each of these cases in turn.

\section{1. 'Fronted' and 'Parenthetical' Adverbs: Wyner (1994, 1998)}

As noted above, Wyner presents various adverb data that he takes as evidence against the 'association' claim, and in favour of an analysis on which the 'higher' and 'lower' readings that we have been discussing are available to 'manner' adverbs in any position that they may occupy in a syntactic tree (Wyner 1994: 197-98). The data that Wyner presents might be seen to fall into two categories: (i) those involving 'manner' adverbs that, according to him, can occupy VP-internal or -external positions with no shift in meaning; and (ii) those involving 'parenthetical' and 'fronted' 'manner' adverbs, which similarly involve no shift in meaning compared to their 'undislocated' counterparts. These are illustrated in (18) and in (19)-(20), respectively: ${ }^{2}$

(18) a. Kim passionately had kissed Sandy.

b. Kim had passionately kissed Sandy.

c. Kim had kissed Sandy passionately.

(Wyner 1998: $\S 1.3,(12 b-d))$

2 Note that the judgements are Wyner's - speakers whom I consulted found many of the sentences in (19) (20), in particular, rather awkward. (See the following note.) 
(19) a. Kim had kissed every man, rudely, on his birthday.

b. Kim congratulated no one, rudely, on anyone's birthday.

c. Kim kissed, stupidly, the tall, blonde woman who wore one black shoe.

d. Kim, rudely, had kissed Sandy.

e. Kim had, rudely, kissed Sandy.

f. Kim had kissed Sandy, rudely.

(20) a. Passionately, Kim had kissed Sandy.

b. Rudely, Kim had kissed Sandy.

Let us first consider Wyner's examples of 'higher' and 'lower' adverbs, as given in (18b $-c)$, since his claim that they exhibit no contrast is at odds with what we have observing for such pairs so far. (The further complications associated with the adverb position in (18a) will be addressed in $\$ 3.2$ below.) Wyner's specific claim about the availability of 'higher' and 'lower' readings for 'manner' adverbs is that each reading is always available, although one will be 'prominent' and one 'secondary' in a given instance (see Wyner 1994: 197-98). The basic difficulty with this claim, as revealed by the data in $\$ \S 2.1-2.2$, is that there are many cases in which a 'higher' or 'lower' occurrence of a 'manner' adverb actually leads to unacceptability - a result that Wyner's account simply does not predict. However, even when a 'higher' or 'lower' occurrence does not lead to acceptability, it appears (pace Wyner) to be associated with only one reading, and not with 'primary' and 'secondary' readings.

This can be brought out by the sentences in $(18 \mathrm{~b}-\mathrm{c})$, which (as just noted) Wyner takes to be synonymous. What is crucial here is that the descriptions of kissing events with which Wyner illustrates his claim make the possibility of discerning 'higher' and 'lower' readings rather small in any case. This is because kissing can both be done in a passionate manner and be a sign of someone's being passionate; and it is difficult to disentangle, linguistically or otherwise, passionate kissing from kissing that (say) bespeaks passion. For this reason, the distinction between 'higher' and 'lower' readings for such sentences will be largely neutralized. However, it is straightforward enough to find sentences that both distinguish these two readings and demonstrate their association with two different positions. These include the ones given below:

(21) a. Kim had passionately chosen love over happiness.

b. \#Kim had chosen love over happiness passionately.

(22) a. Kim had done his work passionately.

b. \#Kim had passionately done his work.

The existence of such examples, many more of which were already adduced above, casts serious doubt on Wyner's synonymy claim. However, because his claim also draws its support from another set of adverb data - namely, that involving 'parenthetical' and 'fronted' adverbs -, and because these data pose a much greater challenge to the 'association' claim, we need to consider them carefully before we can properly assess his claim.

Let us turn, then, to the examples in (19) - (20). Here, interestingly, we find 'higher' readings strongly favoured for all occurrences of both rudely and passionately. This pattern 
loses some of its sharpness when we test these adverbs against a broader range of VPs, ${ }^{3}$ in which case we discover a strong favouring of 'lower' readings for some VPs and the availability of both readings for others. 'Higher' readings nevertheless predominate, particularly for 'fronted' cases and for 'parentheticals' that occur early in the sentence:

(23) a. Kim had done his work, passionately. ('lower' reading strongly favoured)

b. Kim had, passionately, done his work. ('higher' reading strongly favoured)

c. Kim had chosen love over happiness, passionately.

('higher' reading strongly favoured)

d. Kim had, passionately, chosen love over happiness.

('higher' reading strongly favoured)

(24) a. Your son spoke to my wife, rudely. ('lower' reading strongly favoured)

b. Your son spoke, rudely, to my wife. (both readings possible)

c. Your son, rudely, spoke to my wife. ('higher' reading strongly favoured)

d. Yesterday, you left the meeting at noon - rather rudely, I might add.

i. You had no business leaving then. ('higher' reading)

ii. You interrupted the chairman with you noisy departure. ('lower' reading)

(25) a. Rudely, you left the meeting at noon. ('higher' reading strongly favoured)

b. Rather rudely, I must say, your son spoke to my wife. (same)

c. Passionately, Kim had chosen love over happiness. (same)

d. Passionately, Kim had done his work. (same)

These data are, of course, consistent with Wyner's claim that 'higher' and 'lower' readings are available up and down the syntactic tree, and with his (1994: 198) remark that sentences read 'without comma intonation [...] seem more clearly to have the manner interpretation' whereas those 'read [...] with comma intonation [...] more clearly have the event intrepretation.' From this remark, it appears that Wyner takes 'parenthetical' and 'non-parenthetical' occurrences of adverbs to have essentally the same syntctic status, differing from each other only in superficial intonational features. However, such a view not only makes the connection between 'comma intonation' and the 'eventive' reading completely arbitrary - as far as Wyner's analysis goes, the opposite pattern, in which comma intonation made 'manner' readings salient, is just as possible - but fails to acknowledge the distinct possibility that adverbs read with 'comma intonation' are indeed 'parenthetical'. ${ }^{4}$ As such, they would have an exceptional phrase-structural status (see e.g. McCawley (1988: 39ff.)), which might be the true source of the patterns just given.

An account of the sentences in (23)-(24) that invokes the 'parenthetical' status of the adverbs contained in them might start with the assumption that parenthetical expressions serve, generally speaking, to qualify or comment on the statements with they are associated.

3 Note that embedding these adverbs in more elaborate parenthetical expressions, as illustrated below, makes their 'parenthetical' use more natural:

(i) a. Your son spoke - rather rudely I might add - to my wife.

b. Your son - rather rudely I might add - spoke to my wife.

4 Or otherwise 'dislocated', as I shall be suggesting below for the 'fronted' cases. 
On this view, the more salient reading of 'parenthetical' instances of 'manner' adverbs would be the 'higher' one, since it is on this reading that, by hypothesis, these adverbs serve to comment on the situation designated by the VP. Since 'lower' readings, by hypothesis, help to establish the actual situation being referred to in the first place, the availability of this reading for 'parenthetical' occurrences should be much rarer, arguably serving only to express an afterthought. In certain cases, however, both readings are available, as suggested by the sentence in (24d). The key here is that both readings should, in principle, be available. However, this is not for the reasons suggested by Wyner, but because these elements are not fully integrated into phrase structure, and as such do not stand in any direct hierchical relation to the elements to their left and right in a sentence. It follows that 'parenthetical' adverbs do constitute an important exception to the 'association' claim, but one which points more clearly to their exceptional syntactic status than to a shortcoming in the 'association' claim itself.

The 'fronted' adverb data in (25) point us in the same direction. Notwithstanding recent analyses of 'fronted' elements as occupying positions that are fully integrated into phrase structure (see e.g. Rizzi 1997), such elements seem to bear a close resemblance to 'parenthetical' adverbs, displaying many properties that suggest a looser connection to the sentences with which they are construed. Most relevant here is the range of readings that 'fronting' permits for 'manner' adverbs, as demonstrated in (26). These include, in addition to the various 'sentential' readings described by Bellert (1977) and others $((26 a-c))$, both 'eventive' and 'manner' readings ((26d-f) and (26g), respectively) $:^{5}$

(26) a. Frankly, Joe is a fool.

b. Happily, Sam sucks lemons. (cf. Sam sucks lemons happily.)

(Thomason \& Stalnaker 1973: 205, in McConnell-Ginet 1982: 148, (9a))

c. Quite simply, life cannot be the same.

(Biber et al. 1999: 558)

d. Slowly, everyone left.

(McConnell-Ginet 1982: 175, (70b))

e. Reluctantly, Mary was instructed by Joan.

(ibid., 145, (1b))

f. Automatically she backed away.

(Biber et al. 1999: 553)

g. Sternly, the headmaster lowered his spectacles from the bridge of his nose.

(Ernst 1984: 293, (193a))

While the 'sentential' readings of the adverbs in $(26 \mathrm{a}-\mathrm{c})$ - in particular, the speaker-oriented reading of frankly - might be lexicalized, the readings of the adverbs in $(26 \mathrm{~d}-\mathrm{g})$ are very unlikely to be: brief inspection of these cases reveals them to be our familiar 'higher' and 'lower' readings, now associated with a new position.

This last observation suggests that these adverbs have simply been moved from positions internal or external to the VP. Such a possibility loses its plausibility, however, in the face of the clear contrast in acceptability between these adverbs and uncontroversially moved adverbial elements, as demonstrated in (27):

(27) a. How quickly did John say that he ran home?

b. Never had John run so quickly.

c. *Quickly, John said that he ran home.

(Shaer 1998: $\$ 4,(36)$ )

5 The 'VP-internal modifier' behaviour in question was, in fact, noted by McConnell-Ginet (1982: 156, n.13). 
In Shaer (1998), I suggested on the basis of these and other data that 'fronted' adverbs were base-generated sentence-initially as 'hanging topic left dislocation' structures (e.g. Anagnostopolou 1997), and most resembled structures like the following ones:

(28) a. I said that my father, he was tight as a hoot-owl.

(Ross 1967; in Anagnostopolou 1997: 167, (40b))

b. And your appointment, did you arrive on time?

(Isard 1974: 246)

As such, their interpretation was highly dependent on their own lexical properties and on their grammatical and situational context. ${ }^{6}$

One question that such a 'dislocation' claim does not address, however, is why the interpretation of elements in this position should be so dependent on context simply because these elements are 'dislocated' from their usual positions. One promising answer to this question has been offered by Kempson \& Meyer-Viol (1998), who describe 'dislocation' structures in terms of 'a model of language understanding in which interpretation is defined as a process of progressively building up a logical form on a left-right basis' for a given string (ibid., §5). This involves the creation of nodes in a tree representation corresponding to the logical form for that string, "each node com[ing] into being with some set of requirements (for annotations on that node), which must then be progressively satisfied by annotations supplied by that string.' As such, a well-formed logical form for a string must have 'the requirements associated with all nodes [...] satisfied the moment the string has been completely traversed' (ibid., §1).

On this model, the intuition that 'dislocated' constituents are not fully integrated syntactically into a sentence yet express the same proposition as their 'undislocated' counterparts can be captured through the assignment of 'initially weak tree descriptions' to the former constituents, 'which are subsequently updated' (ibid., §5). Thus, 'left dislocation' constructions like that in (29) will have tree descriptions in which the 'dislocated' constituent projects a logical term on a node whose position in the tree has not yet been defined - this 'reflect[ing] the fact that that term does not yet have a definite role in the (partial) logical form':

(29) The woman I met in London, John interviewed at length.

(ibid., (1)))

Once the tree position of this 'dislocated' constituent is fixed, the sentence containing it will end up "project[ing] a propositional structure identical to that projected by the "basic" string without dislocated constituents' (ibid.).

Kempson \& Meyer-Viol implement this proposal in terms of inference rules that apply to descriptions of partial trees - that is, 'structure[s] that can be embedded in complete binary tree[s]' (ibid., \$2.1). Nodes in these trees are represented by ordered pairs of lists of 'requirements', 'the TODO list', and 'annotations', 'the DONE list'. Processing involves a set of transitions from a single root node with a TODO list containing only the type $t$ and the first word of a string to a root node with type $t$ on its $D O N E$ list, nothing left on its TODO list, and no words remaining (ibid.). The authors elaborate on these basic components in order to provide an account of various attested 'dislocation' structures, which differ from each other, for example, in containing or not containing a resumptive element in the host sentence and in displaying a 'tighter' or 'looser' connection between the 'dislocated' constituent and the host sentence. These differences are captured by three different means: (i) by having nodes project

6 See Maienborn (1998) for similar remarks regarding the interpretation of 'fronted' locative modifiers. 
information on TODO lists or DONE lists; (ii) by having one tree linked or not linked to another, where in the former case information is transferred from one tree to another and thereby 'constrain[s] subsequent tree development'; and (iii) by having the determination of a location for unfixed nodes restricted to the 'local tree' (that is, the tree in which this node has been created) or 'somewhere in the subsequent global tree' (ibid., §3). The differences between, for example, $w h$-movement and 'clitic left dislocation' accordingly involve differences in the kind of information that 'unfixed' nodes project and the kind of tree structures that are a consequence of this difference. More specifically, the former case involves only 'the projection within a tree structure of a node annotated with a formula and lacking only a fixed tree position'; whereas the latter involves both 'the linkage of a tree to (the representation of) the dislocated constituent', and the dislocated constituent's projection of a formula as a requirement on some [as] yet unfixed node' within this tree (ibid., §3).

'Fronted' adverb constructions appear to resemble the former structures in that they, too, involve only an unidentified internal tree relation, with no linking of a 'dislocated' node to a tree that must contain a resumptive element. On the other hand, given the unacceptability of sentences like that in $(27 \mathrm{c})$, 'fronted' adverbs clearly do not tolerate 'long-distance' dependencies of the kind that we find with $w h$-movement structures. An analysis of 'fronted' adverbs would thus have to capture the very tight locality requirement imposed by 'fronted' adverbs on the clauses with which they are construed.

At this stage I cannot offer an explicit application of Kempson \& Meyer-Viol's model to 'fronted' adverbs, and must leave the development of such an analysis for future research. However, the various features of this model that I have sketched suggest that such an analysis would be a promising one. Unlike either Wyner's approach or those couched in terms of 'discourse-related' functional projections, this one has the means to capture directly the syntactically and semantically loose connection between 'fronted' adverbs and their host sentences. At the same time, it is able to assign the same propositional structure to sentences with 'fronted' and 'non-fronted' adverbs, and thus to account for the synonymy facts that we observed above. Moreover, because it models interpretation as a process of building up logical forms, it assigns a key rôle to inference in the assignment of an interpretation to a string, and is thus naturally suited to the description of a phenomenon in which context and word meanings figure so prominently in the fixing of interpretations. Finally, such a model would appear to lend itself to a treatment of 'parenthetical' adverbs (among other 'parethetical' elements), with which 'fronted' adverbs, as suggested above, have a good deal in common, thereby permitting a unified analysis of two kinds of syntactically 'exceptional' adverb positions.

What we have found in this section, then, is that the range of 'manner' adverb data with which Wyner launches his challenge to the 'association' claim turn out to have plausible analyses that are broadly consistent with this claim, and thus cannot be seen to support his alternative. Wyner is certainly correct in asserting that the readings associated with 'parenthetical' and 'fronted' adverbs are incompatible with rigid 'association' claims, according to which every adverb in every sentence can be associated with a unique base position in a syntactic tree. Yet he overlooks compelling reasons for treating these occurrences of 'manner' adverbs as syntactically exceptional, and thus as falling outside the purview of a more plausible 'association' claim. Once we consider the possibility that such adverbs have the readings that they do because they occupy positions with no fixed relation to the sentence, then we can see their inconsistency with the 'association' claim in a rather different (and brighter) light. 


\section{2. 'Non-contrasting' Positions in Auxiliary Projections}

The adverb data examined above by no means exhaust those taken as evidence against the 'association' claim. Another sort, which we turn to in this section, involves adverb positions in the auxiliary verb complex, as illustrated below:

(30) a. She rudely will be leaving the meeting early.

b. She will rudely be leaving the meeting early.

c. She will be rudely leaving the meeting early.

(31) a. She rudely will have left the meeting early.

b. She will rudely have left the meeting early.

c. She will have rudely left the meeting early.

(32) a. She rudely has left the meeting early.

b. She has rudely left the meeting early.

(33) a. She rudely has been leaving our meetings early.

b. She has rudely been leaving our meetings early.

c. She has been rudely leaving our meetings early.

Although these postions have been widely discussed in the adverb literature (e.g. Jackendoff 1972: 75ff.; Ernst 1984: 265ff.; Travis 1988), their syntactic status and their implications for the 'association' claim remain far from clear. The occurrence of adverbs in some of these positions result in sentences that are, admittedly, rather awkward; however, none seems awkward enough to suggest ungrammaticality. Both this availability and this awkwardness suggest a syntactic representation of these positions as adjunction structures: ${ }^{7}$ we might speculate that if such positions are optionally adjoined - and thus do not represent privileged 'purpose-built' positions for these adverbs - , they might be more at the mercy of prosodic constraints that favour certain word orderings over others. This matter of syntactic structure I shall, however, leave for future research, and focus instead on the challenge that these data pose for the 'association' claim, given their demonstration that a given adverb may occur in a range of different positions with no discernible difference in meaning.

In Shaer (1998: §3), I argued that such synonymy was consistent with a looser 'association' claim on which the interpretation of a particular adverb was not determined directly by its phrase-structural position, but was instead guided by its relation to the syntactic projection of 'event structure'. On the proposal that I sketched there, the head of the main VP designated a property or relation; this head together with its arguments, which constituted the main VP, designated a temporally unspecified situation; and a tensed or otherwise temporally specified VP designated a temporally specified situation. While I noted that auxiliary verbs, too, contributed to the temporal and aspectual description of a sentence, I took the main VP to be the basic designator of a situation. This picture of 'event structure' suggested that no interpretative effect accrued to the placement of 'manner' adverbs in higher or lower VP-external

7 This (conservative) view of adverb positions, which I adopted in Shaer (1998: §3), has also recently been advanced by Ernst (e.g. 1998). 
positions because these adverbs predicated some property of the very same situation whether they were in higher or lower positions.

Further investigation of these cases, however, reveals that the occurrence of 'manner' adverbs in higher or lower VP-external positions may be associated with interpretative contrasts after all. Consider the pair of sentences in (34):
a. Louisa rudely has left the party without saying good-bye.
b. Louisa has rudely left the party without saying good-bye.

These sentences seem, at first sight, to be fully interchangeable. Closer inspection, however, suggests that they assert subtly different propositions, related to the contribution made by the perfect form (the auxiliary have together with the past participle) in each sentence. These are (i) that Louisa is rude to have left without saying good-bye, and (ii) that she has been rude to leave without saying good-bye, respectively. Such a contrast is consistent with an analysis of the English perfect form advanced by Kamp \& Reyle (1993: 566ff.) among others, on which it designates a state 'which results from the occurrence of [the] event' designated by the main VP (ibid., 568). On this view, perfect and non-perfect forms actually describe different situations; so that the same 'manner' adverb predicates the same property of two different situations in (34a) and (34b), respectively, thereby giving rise to sentences with distinct interpretations. Note that the observed contrast between (34a) and (34b) is also consistent with the more 'temporal' approach to 'event stucture' adumbrated in Shaer (1998: §3), according to which perfect forms specify the 'post-time' of a situation designated by the main VP (see e.g. Klein (1994)). Here, the semantic difference between (34a) and (34b) would again rest on a distinction between the situations to which the 'manner' adverb predicates some property, but one constituted solely by a difference in the temporal locations of the situations to which the adverb is related, rather than in the kind of entities designated by the respective VP complexes in these sentences.

A comparison of these two approaches to the differences just described is beyond the scope of this study. We might note, however, that the latter, 'temporal', approach readily extends to cases in which 'manner' adverbs occupy different positions with respect to the auxiliary form will:

(35) a. Louisa rudely will be leaving the party without saying good-bye.

b. Louisa will rudely be leaving the party without saying good-bye.

The resulting contrast here is similar to that displayed in (34), involving the respective assertions (i) that Louisa is rude in that she will be leaving without saying good-bye, and (ii) that she will be rude in leaving without saying good-bye. In this case, though, the contrast cannot be attributed to a difference in the kinds of situations that are referred to, so a 'temporal' solution appears to be the only one available.

Note that even these attenuated contrasts do not emerge in every case in which one sentence differs from another in its placement of a 'manner' adverb with respect to an auxiliary. In particular, the placement of the adverb either to the left of or between the two elements that constitute progressive forms does not lead to any contrast, as far as I can tell; and the placement of the adverb to the left of a present or past progressive form leads only to degraded acceptability compared both to the placement of the adverb between the two elements in the progressive form and to analogous future progressive forms. These patterns are given in (36) and (37), respectively: 
(36) a. Louisa will rudely be leaving the party without saying good-bye.

b. Louisa will be rudely leaving the party without saying good-bye.

(37) a. ??Louisa rudely is/was leaving the party without saying good-bye.

b. Louisa is/was rudely leaving the party without saying good-bye

c. Louisa rudely will be leaving the party without saying good-bye.

The absence of a contrast in (36) may be related to the status of progressive forms as a kind of 'discontinuous constituent', which arguably neutralizes the effect of this difference in adverb placement. The pattern in (37), on the other hand, has no such explanation, and may instead be related to prosodic constraints favouring the placement of a stress-bearing element after the unstressed auxiliary element. These remarks are, of course, highly speculative, and a detailed investigation of these and related patterns of interpretation and acceptability remains to be undertaken. What nevertheless emerges from consideration of the data in (30)-(37) is that differences in the positions of adverbs even in the auxiliary complex may lead to differences in interpretation, given the distinct relation that these adverbs may bear to the syntactic projection of 'event structure'. While these data involve very subtle contrasts, these are real enough to demonstrate that the data are consistent with the 'association' claim.

\section{3. 'Neutralization' of Contrasts}

So far, we have seen that various adverb data taken to be at odds with the 'association' claim can be reconciled with it, either through an appeal to the exceptional character of particular adverb positions or through a demonstration that structurally-determined interpretative contrasts do emerge even in contexts where they are not generally recognized to. This suggests that the linguistic system makes an interpretative contrast between 'higher' and 'lower' positions available, although the realization of this contrast depends on additional factors - in particular, the compatibility of 'higher' or 'lower' readings with a given adverb and VP (as described in \$2.1) and with the 'argument-structure' requirements of verbs with ar $\cdots$ b complements (as described in $\S 2.2 .1$ ).

Of course, this conclusion is not incompatible with the existence of 'manner' adverbs with non-contrasting 'higher' and 'lower' interpretations, about which something more, or something else, would need to be said - essentially what we concluded about adverbs in 'parenthetical' and 'fronted' positions. One class of 'manner' adverbs that would be a good candidate for such treatment is 'agent-oriented' adverbs (e.g. Ernst 1984: 26), exemplified below: 8

(38) a. John has answered their questions cleverly.

b. John has cleverly answered their questions. (Cinque 1996: §1.4, (83a, c))

(39) a. Joe had left the door unlocked deliberately/intentionally/reluctantly.

b. Joe had deliberately/intentionally/reluctantly left the door unlocked.

(40) a. Oedipus knowingly married Jocasta.

(McConnell-Ginet 1982: 152, (21a))

b. Oedipus married Jocasta knowingly.

8 These adverbs are called 'subjet-oriented' by Jackendoff (1972: 82) and 'passive-sensitive' by McConnellGinet (1982: 145). 
Observation of data like these have motivated proponents of 'association' and 'anti-association' approaches alike to advance synonymy claims for 'higher' and 'lower' occurrences of these adverbs. Cinque (1996) assigns a single base-generated position to the two occurrences, relating one to the other via movement. Wyner (1994), though pursuing a diametrically opposed 'anti-association' claim, likewise assigns the two occurrences a uniform analysis, distinguishing the readings of these adverbs from 'manner' and 'eventive' readings by making explicit their dependence on particular 'thematic participants' in the situation designated by the sentence (ibid., ch. 3). Both approaches, despite their substantial differences, highlight a crucial fact about 'lower' and 'higher' readings as they apply to this class of adverbs. This is that these two readings - which we have taken to involve, respectively, restricting the range of situations referred to (in particular, by specifying the manner in which some action occurs or is performed); and predicating some property of the situation as a whole - appear to blur with 'agent-oriented' adverbs. If, for example, we attempt to apply the 'manner' versus 'eventive' distinction to the sentences in (38), we might arrive at a paraphrase of the 'lower' reading for (38a) that invokes 'a manner that suggests that the agent was clever in answering the questions'. But this looks suspiciously like the 'eventive' paraphrase whereby 'the agent was clever in answering the questions', and begs the question of whether these are really distinct readings after all.

Similar remarks apply to the class of adverbs exemplified below, which Ernst (1984: 94) has described as 'pure manner' adverbs:"

(41) a. He brilliantly performed the trick.

b. He performed the trick brilliantly.

(42) a. He loudly shuffled the papers.

b. He shuffled the papers loudly.

Like 'agent-oriented' adverbs, these bear no clearly distinguishable 'manner' and 'eventive' readings, but arguably for a very different reason: namely, that these adverbs, as Ernst's label implies, always serve basically to specify the manner of action (even though this manner may be more or less directly perceptible).

Despite the appeal of uniform analyses of the 'higher' and 'lower' occurrences of the adverbs given in (38)-(40) and (41)-(42), what I shall actually be proposing is something quite different. I shall first show that, first appearances notwithstanding, these adverbs are also liable to 'higher' and 'lower' contrasts after all, which can be brought out most readily by VPs that lead to contrasts in the acceptability of 'higher' and 'lower' occurrences. This suggests that these contrasts cut across standard 'manner', 'pure manner', and 'agent-oriented' adverbs alike; and thus that these classes of adverbs have more in common with each other than is generally recognized. What it also suggests, though, is that the 'eventive'/'manner' contrast, which we have been assuming throughout our discussion, does not readily extend to the 'higher' and 'lower' readings attested here, which appear to require a different kind of description.

9 This pattern is also attested for frequency adverbs, which I shall not be considering here:

(i) a. New Yorkers frequently take taxis.

b. New Yorkers take taxis frequently.

(ii) a. Texans often drink beer.

b. Texans drink beer often. 
To proceed, let us take a closer look at 'agent-oriented' adverbs like intentionally and knowingly. Although the patterns presented above offer a compelling picture of these adverbs, this picture turns out not to be an accurate one, given pairs of sentences like the following ones:

(43) a. You tripped me intentionally - I could see you waiting for me.

b. ??You intentionally tripped me - I could see you waiting for me.

a. Oedipus replied knowingly.

b. \#Oedipus knowingly replied.

'Higher' occurrences in both cases are distinctly odd. Yet this contrast does not obviously follow the familiar 'eventive' versus 'manner' pattern: both sentences in (48) seem paraphraseable as 'Your tripping me was intentional'; and both sentences in (49) seem paraphraseable as either 'Oedipus was knowing in his reply' or 'Oedipus replied in a knowing way'.

The picture of 'pure manner' adverbs offered above likewise gives way to one resembling that of standard 'manner' adverbs. The (a) and (b) sentences in (45) are compatible only with the continuations in (i) and (ii), respectively, revealing a clear difference in the contribution of 'higher' and 'lower' adverbs. The (a) and (b) sentences in (46) display a similar contrast.

(45) a. The prisoner proclaimed his innocence loudly.

i. He woke up all the other prisoners.

\# ii. He really believed that he had been framed.

b. The prisoner loudly proclaimed his innocence.

\# i. He woke up all the other prisoners.

ii. He really believed that he had been framed.

(46) a. He played poker brilliantly.

b. \#He brilliantly played poker.

Such adverb data indicate that 'agent-oriented' and 'pure manner' adverbs might have more in common with other 'manner' adverbs than the analyses mentioned above suggest. Indeed, we find further support for this contention from the observation that the interpretation of both 'pure manner' and standard 'manner' adverbs is often as dependent on the 'thematic participants' in a situation as is that of the 'agent-oriented' adverbs that Wyner and others analyse as 'thematically dependent'. ${ }^{10}$ To see this, consider the following scenario: we witness Yokel, unbeknownst to his dinner companion, Vokel, spitting his olive pits into Vokel's soup; and then Vokel complaining about this in a very rude fashion to the waiter. We can certainly report the pit-spitting by means of (47a) and the complaining by means of (47b):

(47) a. That was rude.

b. What rude complaining!

10 This is made explicit in McConnell-Ginet's (1982) and others' analyses of 'higher' adverbs. 
But the correct interpretation of such utterances involves attributing the rudeness of the pitspitting event and the rudeness of the manner of addressing the waiter specifically to the agents of these respective events, as indicated in the following paraphrases:

(48) a. That (i.e. the pit-spitting) was rude of Yokel.

b. It was rude of Yokel to spit his olive pits into Vokel's soup.

c. Yokel was rude to spit his olive pits into Vokel's soup.

(49) a. The way that Vokel complained was really rude.

b. Vokel's complaints were made so rudely.

Similar remarks apply to 'pure manner' adverbs. Although a sentence like (50a), for example, can be construed as simply predicating loudness of a music-playing event, a sentence like $(50 \mathrm{~b})$, which designates a situation with an agent, requires us to attribute loudness specifically to this agent:

(50) a. Music was playing loudly.

b. The old man complained to us loudly.

Such similarities between the different classes of adverbs under consideration lend further credence to a treatment of 'agent-oriented' and 'pure manner' adverbs that relates them more directly to standard 'manner' adverbs - and, in particular, distinguishes 'higher' and 'lower' readings for them.

Of course, the question that now arises is what kind of treatment of 'higher' and 'lower' readings will actually generalize across these classes of adverbs, which despite certain similarities are far from identical. We have already seen that a 'manner'/eventive' contrast does little justice to the data in question. Another possibility that we might entertain is a contrast between 'situation-internal' and 'situation-external' readings, as invoked in Shaer (1998: §3) and used to good effect by Maienborn (1998) in analysing locative modifiers. Brief reflection, however, suggests that this will be of little help either, since it is unclear how the notion 'external to the situation' can apply to 'higher' occurrences of 'agent-oriented' or 'pure manner' adverbs. Although neither of these possibilities seems to hold much promise, there is at least one other available which, I shall be arguing, does do so: this is Peterson's (1997) distinction between 'restrictive' and 'non-restrictive' modification, which I shall be describing below.

\section{Restrictive and Non-restrictive Modification: Peterson (1997)}

In the previous section, we saw good evidence for a 'higher'/'lower' contrast for 'agentoriented' and 'pure manner' adverbs, but did not solve the puzzle of the nature of this contrast as it pertained to these adverbs. In what follows, I shall be arguing that a general solution to this puzzle can be found in Peterson's (1997: 283ff.) distinction between 'restrictive' and 'non-restrictive' adverbial modification, which readily applies to the readings associated with 'higher' and 'lower' occurrences of the adverbs that we have been considering in this study. 
Peterson claims that the readings that we have been referring to as 'lower' and 'higher' are counterparts of the 'restrictive' and 'non-restrictive' readings found with relative clauses and adjectives, as illustrated in (51):

(51) a. The men who were tired ate strawberries.

b. The men, who were tired, ate strawberries.

c. The tired men ate strawberries. $=(a)$ or $(b)$

(ibid., 231-32, (21), (22))

Peterson motivates his claim primarily by considering adverbs in event nominals, which may have either 'restrictive' or 'non-restrictive' readings, as shown in these examples:

(52) a. The Titanic('s) sinking rapidly caused great loss of life. =

i. 'The Titanic's sinking being rapid caused great loss of life.' ('restrictive')

ii. 'The Titanic's sinking, which was rapid, caused great loss of life.' ('non-restrictive')

b. The Titanic('s) sinking quietly caused great loss of life. $=$

i. \#'The Titanic's sinking being quiet caused great loss of life.' ('restrictive')

ii. 'The Titanic's sinking, which was quiet, caused great loss of life.' ('non-restrictive')

(based on ibid., 233-34, (25)-(27))

These two readings can be understood as follows: the 'restrictive' reading amounts to a constraining of the reference of the syntactic constituent being modified; whereas the 'non-restrictive' reading 'amounts to a double assertion', which in the two cases given in (51) and (52a), respectively, is 'that all men ate strawberries and that they (all the men) were tired'; and 'that the Titanic's sinking caused great loss of life and that the sinking was a rapid one' (ibid., 234$35)$.

Peterson illustrates the restrictive reading of the adverb rapidly in a VP structure with the sentence in (53b), showing how a discourse like that in (53a) can make this reading salient:

(53) a. Lots of ships have sunk at sea and very few of their passengers or crew were killed.

What caused such a great loss of life in the sinking of the Titanic?

b. The Titanic sank rapidly.

Interestingly, Peterson offers his 'restrictive'/'non-restrictive' distinction only as a way to capture two different readings that adjectives and adverbs may receive, and does not suggest that these two readings might be related to 'higher' and 'lower' adverb positions. In fact, he takes the sentence (54b), with a 'lower' adverb, to be amenable to the 'non-restrictive' reading also, which he claims can be brought out by the following discourse context: 11

(54) a. What memorable events involving large ships in the North Atlantic can you think of?

b. Well, I crossed the Atlantic in 1957 aboard the America. But I remember some more notable events. The Lusitania was sunk by a German submarine in 1915. Also, the Titanic sank rapidly. It hit an iceberg.

(based on ibid., 237, (36), (37))

11 I have altered the wording of Peterson's original example to make it sound more natural. 
Despite his efforts to make the 'non-restrictive' reading salient in this discourse, I do not believe that he succeeds: the reading in question still remains inaccessible. What brings out the desired reading much more readily is the occurrence of the adverb in the 'higher' position (together with a VP that is more fully parallel to that describing the sinking of the Lusitania):

$b^{\prime}$. ... Also, the Titanic rapidly sank off the coast of Newfoundland.

Here, we obtain the kind of 'doube assertion' that Peterson associates with the 'non-restrictive' reading: that the Titanic sank off the coast of Newfoundland and - 'almost parenthetically', as Peterson notes of the analogous reading of (52a) - that its sinking was rapid.

Another of Peterson's illustrations of the 'restrictive'/"non-restrictive' contrast is given in (55) - (56) below. ${ }^{12}$ Here, too, his overlooking of structural position as a possible factor in this contrast underscores its importance. The discourse in (55a) is meant to bring out the relevance of the candle's brightness; whereas that in $(56 \mathrm{a}-\mathrm{b})$ is meant to describe the brightness as incidental, and to make the 'candle's burning in itself' the likely cause of the curtains catching fire. However, without the addition of the temporal modifier all evening, (56b) does not have the effect that Peterson attributes to it, as suggested by the alternative continuation in $\left(56 b^{\prime}\right)$ :

(55) a. How could you see any of the notes with only a candle to illuminate the music?

b. The candle was burning brightly.

(56) a. What caused the curtains to catch on fire?

b. Well, there are a number of possibilities. One of the smokers may have dropped a live ash on them. Or, maybe Harold's chafing dish did it. The candle (on the window sill) was burning brightly (all evening). That may have done it.

$b^{\prime}$.... The candle (on the window sill) was burning brightly. That may have done it.

Again, a continuation of the discourse with the adverb brightly in 'higher' position seems more effective in bringing out the 'parenthetical' reading that Peterson has in mind:

$b^{\prime \prime} . .$. The candle (on the window sill) was brightly burning. That may have done it.

The problems that Peterson encounters, then, in illustrating 'restrictive' and 'non-restrictive' readings of adverbs with VPs make for compelling evidence that these readings are indeed structurally determined. This is because the implausible readings that he attributes to particular occurrences of adverbs are precisely those that an account distinguishing 'higher' and 'lower' readings on structural grounds predicts to be unavailable.

If we return to the puzzling asymmetries beween 'lower' and 'higher' adverbs that we observed in $\$ 3.3$, repeated as $(57)-(60)$ below, we can see that an analysis of the latter in terms of 'non-restrictive' modification, corresponding to a 'double assertion', is able to capture the unacceptability of 'higher' occurrences in the (b) sentences in (57) - (59) and the interpretative contrast between (60a) and (60b):

12 Again, I have slightly altered the wording of Peterson's original example, replacing simple past tense forms with progressive forms to make it sound more natural. 
(57) a. You tripped me intentionally-I could see you waiting for me.

b. ??You intentionally tripped me-I could see you waiting for me.

(58) a. Oedipus replied knowingly.

b. \#Oedipus knowingly replied.

(59) a. He played poker brilliantly.

b. \#He brilliantly played poker.

(60) a. The prisoner proclaimed his innocence loudly.

i. He woke up all the other prisoners.

\# ii. He really believed that he had been framed.

b. The prisoner loudly proclaimed his innocence.

\# i. He woke up all the other prisoners.

ii. He really believed that he had been framed.

On a 'Petersonian' analysis, the (b) sentences in (57) - (59) can be seen, respectively, to assert that you tripped me, that Oedipus replied, and that he played poker; and to assert 'almost parenthetically' that the tripping was intentional, the reply knowing, and the poker-playing brilliant. It is because these latter assertions are 'almost parenthetical' that each of these (b) sentences is odd: what we expect in each case is the 'restricted' modification of the (a) sentences, which serves to constrain their reference, telling us what kind of tripping you perpetrated (as further clarified by the continuation), what kind of reply Oedipus made, and what kind of poker-playing he did. Similarly, the acceptable (a) and (b) sentences of (60) can be seen to make different assertions and thus to be compatible with different continuations: the former the 'single' assertion that the prisoner proclaimed his innocence in a loud manner; the latter the 'double' assertion that he proclaimed his innocence and 'incidentally' that this proclamation was loud.

Although Peterson (1997) does not offer a formal treatment of the difference between 'restrictive' and 'non-restrictive' adverbial modification, his theory of 'complex events' suggests one way to do so, which appeals to the kinds of events to which 'restrictively' and 'non-restrictively' modified sentences respectively refer. If we invoke Peterson's 'complex event' approach for sentences with 'higher' adverbs, we can understand a sentence like that in (61a), for example, to assert the existence of the complex event of John's-slicing-of-the-meat being careful, which embeds the unique event of John's-slicing-of-the-meat (ibid., 248). Peterson formalizes this 'complex event' analysis as in (67b) (where ' $x$ ' and ' $y$ ' stand for the two events):

(61) a. John carefully sliced the meat.

b. ᄏy Careful (xx Sliced (John, the meat, x), y) (based on ibid., 248, $\left(58^{2}\right)$ )

We can distinguish sentences like that in (61a) from sentences with 'lower' adverbs like that in (62a) by treating the latter in more standard Davidsonian fashion as asserting the existence of a simple event of a certain type. On this analysis, the sentence in (62a) would be assigned the translation in $(62 b)$ : 
(62) a. John sliced the meat carefully.

b. $\exists \mathrm{x}$ (Sliced (John, the meat, $\mathrm{x}$ ) \& Careful (x))

(based on ibid., 244, (55))

The key difference between (61a) and (62a), as highlighted by such an analysis, is that the latter asserts 'that an event of a certain type [exists]', while the former 'contains a reference to that event' (ibid., 244).

This very preliminary sketch of the difference between 'restrictive' and 'non-restrictive' adverbial modification is admittedly silent on a number of important issues in the analysis of 'manner' adverbs, for which I have no concrete answers at present. In particular, it does not incorporate the observation made above, which certainly applies to carefully, that 'manner' adverbs in both 'higher' and 'lower' positions may have an 'agent orientation' (see also Peterson (ibid., 245, 376-77)); nor spells out the differences between standard 'manner', 'pure manner', and 'agent-oriented' adverbs. Moreover, it gives no indication of how these formulae are to be derived from syntactic structure. What it does do, however, is suggest one way to cash out the interpretative contrasts associated with 'higher' and 'lower' adverbs, and thus to proceed in the direction indicated in this study.

\section{Conclusion}

In this study, I have offered substantial evidence that the syntactic position of 'manner' adverbs guides the interpretation of sentences containing them, and thus that Wyner's (1994, 1998) 'anti-association' analysis has missed an important generalization. More specifically, I have demonstrated the robustness of 'higher'/ 'lower' adverb contrasts on the basis of data from various adverbial as well as nominal and adjectival structures; shown that this contrast emerges with classes of adverbs, including 'agent-oriented' and 'pure manner' adverbs, commonly assumed not to display it; and offered a general characterization of this contrast in terms of Peterson's (1997) distinction between 'restrictive' and 'non-restrictive' adverbial modification. I have also suggested that the 'association' claim extends to the various adverb positions available in the auxiliary verb complex, where interpretative contrasts have not, to my knowledge, been previously recognized.

At the same time, I have shown that Wyner's scepticism of standard 'association' accounts is well placed; and, in particular, that 'manner' adverbs in 'fronted' and 'parenthetical' positions do not behave as such accounts would predict them to. However, rather than seeing these data as constituting evidence against the 'association' claim, I have argued that they reflect the exceptional syntactic status of 'fronted' and 'parenthetical' positions, and are amenable to an analysis consistent with this claim.

Although certain key aspects of my analysis remain in embryonic form, what I have offered here has, I hope, still shed some light on a range of empirical issues that have yet to be adequately addressed in the adverb literature. If it has indeed done so, then it will have helped to reveal which approaches to the analysis of adverbs are promising ones and which approaches are not. 


\section{References}

Anagnostopoulou, Elena (1997): Clitic Left Dislocation and Contrastive Left Dislocation. In: - et al. (eds.), Materials on Left Dislocation. Amsterdam/Philadelphia: John Benjamins.

Bellert, Irene (1977): On Semantic and Distributional Properties of Sentential Adverbs. Linguistic Inquiry 8, $337-51$.

Biber, Douglas et al. (1999): Longman Grammar of Spoken and Written English. London: Longman.

Cinque, Guglielmo (1996): Adverbs and the Universal Hierarchy of Functional Projections. Ms., Università di Venezia. [Published as - (1999): Adverbs and Functional Heads. Oxford/New York: Oxford University Press.]

Ernst, Thomas (1984): Towards an Integrated Theory of Adverb Positions in English. Bloomington: Indiana University Linguistics Club.

- (1998): Scope-based Adjunct Licensing. In: Proceedings of NELS 28. Amherst, MA: GLSA.

Isard, Stephan (1974): What Would You Have Done if...? Theoretical Linguistics 1, 233-55.

Jackendoff, Ray (1972): Semantic Interpretation in Generative Grammar. Cambridge, MA: MIT Press.

Kamp, Hans \& Uwe Reyle (1993): From Discourse to Logic. Dordrecht: Kluwer.

Kempson, Ruth \& Wilfried Meyer Viol (1998): Topic and Focus Structures: The Dynamics of Tree Growth. In: Gosse Bouma, Geert-Jan Kruijff \& Richard Oehrle (eds.), Proceedings of FHCC '98, ch. 1.

Klein, Wolfgang (1994): Time in Language. London: Routledge.

Maienborn, Claudia (1998): The Grammar and Pragmatics of Locative Modifiers. Berlin: Humboldt-Universität zu Berlin. Ms.

McCawley, James (1988): The Syntactic Phenomena of English. Chicago: University of Chicago Press.

McConnell-Ginet, Sally (1982): Adverbs and Logical Form: A Linguistically Realistic Theory. Language 58, $144-84$

Peterson, Philip L. (1997): Facts Propositions Events. Dordrecht: Kluwer.

Pustejovsky, James (1995): The Generative Lexicon. Cambridge, MA: MIT Press.

Rizzi, Luigi (1997): The Fine Structure of the Left Periphery. In: Liliane Haegeman (ed.), Elements of Grammar: Handbook in Generative Syntax. Dordrecht/Boston/London: Kluwer.

Ross, John R. (1967): Constraints on Variables in Syntax. Cambridge, MA: MIT doctoral thesis.

Shaer, Benjamin (1998): Adverbials, Functional Structure, and Restrictiveness. In: Proceedings of NELS 28. Amherst, MA: GLSA.

Thomason, Richmond \& Robert Stalnaker (1973): A Semantic Theory of Adverbs. Linguistic Inquiry 4, 195200.

Wyner, Adam Z. (1994): Boolean Event Lattices and Thematic Roles in the Syntax and Semantics of Adverbial

Modification. Ithaca, NY: Cornell University doctoral thesis.
(1998): On Adverbial Modification and Ellipsis. Paper presented at the 20 th annual meeting of the DGfS, Halle.

(1999): A Discourse Analysis for Locative PPs. In: Cathrine Fabricius-Hansen, Ewald Lang \& Claudia Maienborn (eds.), Extended Conference Abstracts: 'Approaching the Grammar of Adjuncts'. Oslo: Department of Germanic Studies, University of Oslo. 